\title{
SPECTRO-RADIOMETER AND SPECTRAL INDICES BASED ENVIRONMENTAL IMPACT ASSESSMENT FOR MANGO TREE LEAVES IN AND AROUND IIT ROORKEE CAMPUS, INDIA
}

\author{
A. Pandey ${ }^{1, *}$ and K. Jain ${ }^{2}$ \\ ${ }^{1}$ Centre of Excellence in Disaster Mitigation and Management (CoEDMM), Indian Institute of Technology Roorkee, Roorkee, \\ India, - pandey.ddt2017@iitr.ac.in \\ ${ }^{2}$ Dept. of Civil Engineering, Indian Institute of Technology Roorkee, Roorkee, India - kjainfce@iitr.ac.in
}

Commission III, WG III/10

KEY WORDS: chlorophyll content, water content, carotenoid content, anthocyanin content, Spectral Indices, Tree Health

\begin{abstract}
:
Cities require and use large quantities of energy and materials, metabolizing them and generating large quantities of waste products and pollutants, resulting in unsustainable urban environments. This polluted urban environment adversely affects ecological integrity and develop stress for different planting sites. Research is needed to evaluate the relative tolerance of tree species against changing urban ecological conditions with specific environment pollutants. The current state of art examines effects of air pollution on four major biochemical perimeters of tree health i.e. chlorophyll content, water content, carotenoid content and anthocyanin content. A Spectro-radiometer and remote sensing indices integrated approach is used to evaluate the impact of deteriorating air quality on mango tree planted in and around the Indian Institute of Technology Roorkee, campus. Four different Vegetation Indices content (Normalized Difference Vegetation Indices, modified normalized difference vegetation index, simple ratio and modified simple ratio) are used for estimate chlorophyll. Five different Water indices (Water index, Normalized water indices-1, Normalized water indices-2, Normalized water indices-3 and Normalized water indices-4) are used for estimating water content. Five different photochemical information indices (Carotenoid concentration index, photochemical reflectance index, Plant senescencing reflectance Index, and Carotenoid concentration index) are used for enumerate carotenoid content. Three different Anthocyanin Reflectance Indices (Modified Anthocyanin Content Index, Anthocyanin Reflectance Index and Modified Anthocyanin Reflectance Index) are used for determining anthocyanin content.
\end{abstract}

\section{INTRODUCTION}

\subsection{Overview}

Tree health is the discipline for precision of vegetation and forestry where we study different biotic and abiotic parameters that affect the life and growth of a tree. Among all the different factors, air pollution is always considered to be the most prominent parameter, which adversely hampers the health of trees. Air pollution spreads serious chemical, physical and biological particles into the atmosphere that poses serious health and environmental threats (Wark and Warner, 1981). Although different studies (Pope et al., 2002; Seaton et al., 1995; Brunekreef and Holgate, 2002) discussed about the impact of air pollution over human but only some (Manion 1981; Yang et al., 2005; Nowak et al., 2016; Mclaughlin et al., 1982; Schulze et al., 2012) had focused on its more scared face where directly or indirectly it affect the health of our planet by vanishing the trees and plants. This situation becomes more dangerous around the industrial areas and national highway where high concentration of hazardous gases directly comes into the contact with surrounding tree leaves which leads to imbalance in their biological and chemical nature. In order to define any mitigation strategy in order to protect the health of the tree it is important to identify different parameters for describing tree health deteriorating.
Leaf is the most vital organ of a tree. Leaves contain pigments to collects different life ingredients and transform them into the food and air supply for a tree. Chlorophyll is the most premium and primary pigment of a leave. They are responsible for conducting photosynthesis and produce food for the tree. Carotenoid and Anthocyanin are secondary pigments. They also participate in photosynthesis activity but as a secondary pigment their role is to control the over temperature and protect the leaves from harmful biological and chemical external agents. Water Content is a vital life elements required for metabolic processes. Its presence within the thresholds is essentially required to conduct smooth functioning for different other organs. Besides the other visual sign (color, shape and size of leaves, insects visible on trees, dead branches and improper growth of tree) measurement of primary and secondary pigments with water content is the best way of inferring the health of a leaf. As these pigments and water content shows unique spectral response, the measurement and processing of their spectral signature will do necessary helps for finding out the more specific impact of changing climatic scenario over the health of leaves and trees.

Remote Sensing is the much established domain of the research which utilizes space driven technologies for collecting the knowledge for an object and also help to implement this knowledge for decision making (Jensen and Lulla, 1987). Several studies conducted in last two decades evidence the unprecedented utilization of remote sensing in evaluation, measuring and management of vegetation and forest resources.

*Corresponding Author 
State of art remote sensing instruments provided different opportunities and growing applications in precision vegetation and forestry. Tree and plant health measurement is one such domain which is extensively getting benefits with multispectral and hyper spectral remote sensing (Mulla 2013; Atzberger 2013; Seelan et al., 2003; Tiwari et al., 2014). These datasets are widely adopted for measuring the greenness or health condition (Xiao and Mcpherson, 2005; Ciesla 2000).

The current study investigates the opportunity of utilizing remote sensing instruments for measuring the health of the leaf. The major objective is to standardize the domain of tree health measurement by collecting different indices utilized to measure specific plant health indicator. For the selected study area, different leaves samples of mango tree are collected in both the unpolluted and polluted environments. These samples are processed with basic remote sensing indices based techniques to generate valuable information regarding the health of tree and their climatic neighborhood.

\subsection{Remote Sensing Techniques for Tree Health Parameters}

Four prominent tree health measuring parameters and their respective measurement indices are as follows:

\subsubsection{Chlorophyll}

Different indices used to measure Chlorophyll $\mathrm{a}$ and $\mathrm{b}$ are presented in the table.

\begin{tabular}{|c|c|c|}
\hline Index Name & Index calculation & References \\
\hline $\mathrm{NDVI}_{705}$ & $\frac{R_{750}-R_{705}}{R_{750}+R_{705}}$ & \multirow{2}{*}{ Chen et al., 2007 } \\
\hline $\mathrm{mNDVI}_{705}$ & $\frac{\mathrm{R}_{750}-\mathrm{R}_{705}}{\mathrm{R}_{750}+\mathrm{R}_{705}-2 \mathrm{R}_{445}}$ & \multirow{2}{*}{ Chen et al., 2007 } \\
\hline $\mathrm{SR}_{705}$ & $\frac{\mathrm{R}_{750}}{\mathrm{R}_{705}}$ & Chen et al., 2007 \\
\hline $\mathrm{mSR}_{705}$ & $\frac{R_{750}-R_{445}}{R_{705}+R_{445}}$ & Chen et al., 2007 \\
\hline
\end{tabular}

Table 1.Remote sensing Indices for Chlorophyll measurement

\subsubsection{Anthocyanin}

Different indices used to measure anthocyanin are presented in the table.

\begin{tabular}{|l|c|l|}
\hline Index Name & Index calculation & References \\
\hline mACI & $\frac{R_{\text {NIR }}}{R_{\text {Green }}}$ & $\begin{array}{l}\text { Gitelson et al., } \\
2009\end{array}$ \\
\hline ARI & $\frac{1}{R_{\text {green }}}-\frac{1}{R_{\text {rededge }}}$ & $\begin{array}{l}\text { Gitelson et al., } \\
2009\end{array}$ \\
\hline mARI & $\left(\frac{1}{R_{\text {green }}}-\frac{1}{R_{\text {rededge }}}\right) * 1$ & $\begin{array}{l}\text { Gitelson et al., } \\
2009\end{array}$ \\
\hline
\end{tabular}

Table 2.Remote sensing Indices for anthocyanin measurement

\subsubsection{Carotenoid}

Different indices used to measure Carotenoid are presented in the table.

\begin{tabular}{|c|c|c|}
\hline $\begin{array}{c}\text { Index } \\
\text { Name }\end{array}$ & Index calculation & References \\
\hline CRI700 & $\frac{1}{R_{515}}-\frac{1}{R_{700}}$ & $\begin{array}{c}\text { Datt 1998; } \\
\text { Sampson et al 2000 }\end{array}$ \\
\hline PRI & $\frac{\left(R_{531}-R_{570}\right)}{\left(R_{531}+R_{570}\right)}$ & Sampson et al 2000 \\
\hline PSRI & $\frac{\left(R_{680}-R_{500}\right)}{R_{750}}$ & Sampson et al 2000 \\
\hline RNIR * & $\frac{1}{\text { CRI550 }_{510}}-\frac{1}{R_{550}} * R_{770}$ & $\begin{array}{c}\text { Datt 1998; } \\
\text { Sampson et al 2000 }\end{array}$ \\
\hline RNIR * \\
CRI700 & $\frac{1}{R_{510}}-\frac{1}{R_{700}} * R_{770}$ & $\begin{array}{c}\text { Datt 1998; } \\
\text { Sampson et al 2000 }\end{array}$ \\
\hline
\end{tabular}

Table 3.Remote sensing Indices for Carotenoid measurement

\subsubsection{Water Content}

Different indices used to measure water content are presented in the table.

\begin{tabular}{|c|c|c|}
\hline $\begin{array}{c}\text { Index } \\
\text { Name }\end{array}$ & Index calculation & References \\
\hline WI & $\frac{R_{900}}{R_{970}}$ & $\begin{array}{c}\text { Penuelas et al., 1996; } \\
\text { Penuelas et al., 1997 }\end{array}$ \\
\hline NWI-1 & $\frac{R_{970}-R_{900}}{R_{970}+R_{900}}$ & Babar et al.,2006 \\
\hline NWI-2 & $\frac{R_{970}-R_{950}}{R_{970}+R_{950}}$ & Babar et al.,2006 \\
\hline NWI-3 & $\frac{R_{970}-R_{890}}{R_{970}+R_{980}}$ & Babar et al.,2006 \\
\hline NWI-4 & $\frac{R_{970}-R_{920}}{R_{970}+R_{920}}$ & Babar et al.,2006 \\
\hline
\end{tabular}

Table 4.Remote sensing Indices for water content measurement

\section{STUDY AREA}

\subsection{Description}

The Indian Institute of Technology (IIT) Roorkee is the oldest engineering education center in India which offers a spectrum of graduation, post-graduation and $\mathrm{PhD}$ courses. Figure 1 shows the concerned area for the current study. Study area lies in and around IIT Roorkee campus in between Longitude 77.20878 E to $77.59275 \mathrm{E}$., Latitude $23.07362 \mathrm{~N}$ to $23.37713 \mathrm{~N}$ and encompasses an area of $267.53 \mathrm{kms}$. Location map specifies the position of one of the busiest national highway NH-58, connecting Dehradun and Delhi. Secondary roads of the Roorkee city are also highlighted with the roads inside IIT Roorkee campus. Table 5 shows the latitude and longitude of the mango tree with the ID assign to each tree. Four different mango trees are selected inside the natural corridor of IIT Roorkee campus and four around NH-58 affected with heavy pollution. 


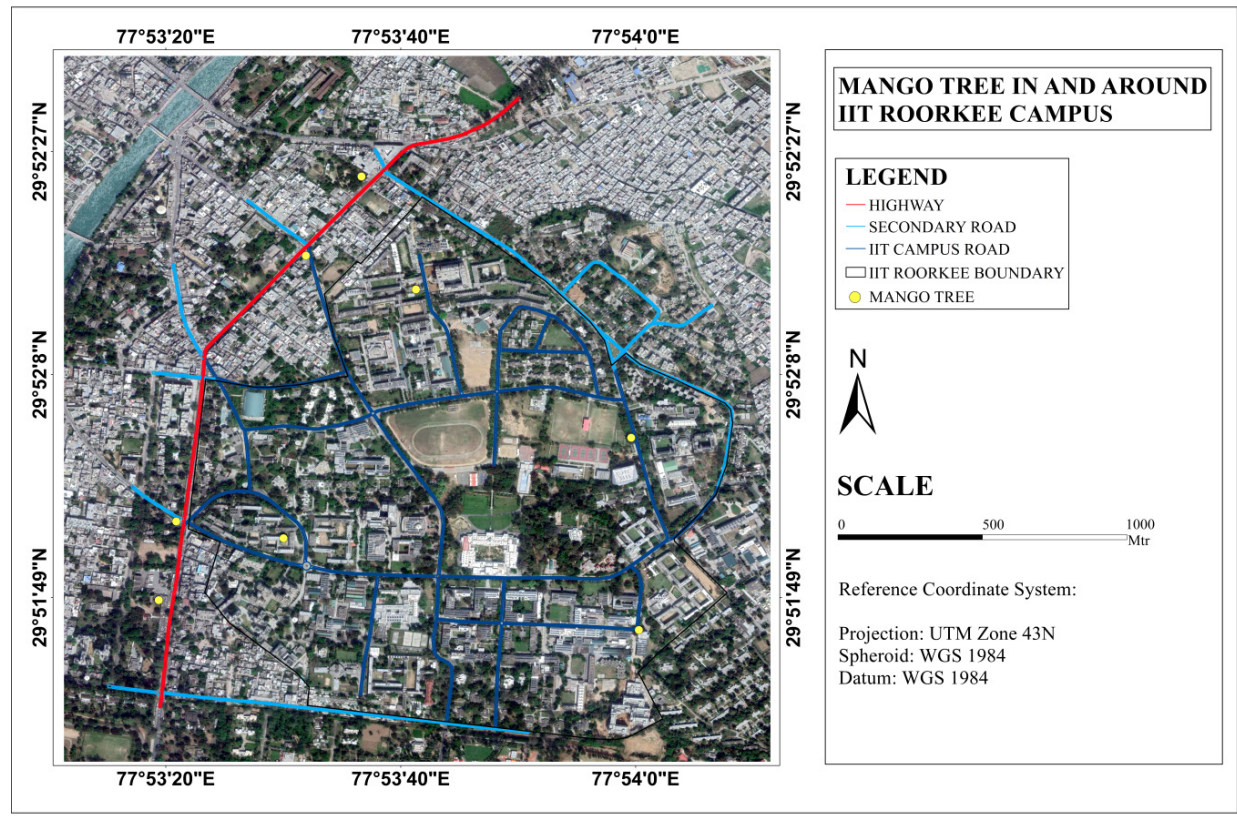

Figure 1.Location map of the study are and position of mango tree

\begin{tabular}{|c|c|c|}
\hline Mango Tree ID & Latitude & Longitude \\
\hline MT-1 & $29.862862^{\circ}$ & $77.900111^{\circ}$ \\
\hline MT-2 & $29.867659^{\circ}$ & $77.899795^{\circ}$ \\
\hline MT-3 & $29.870956^{\circ}$ & $77.894785^{\circ}$ \\
\hline MT-4 & $29.865254^{\circ}$ & $77.891318^{\circ}$ \\
\hline MT-5 & $29.863554^{\circ}$ & $77.888708^{\circ}$ \\
\hline MT-6 & $29.865422^{\circ}$ & $77.889155^{\circ}$ \\
\hline MT-7 & $29.871693^{\circ}$ & $77.892201^{\circ}$ \\
\hline MT-8 & $29.873318^{\circ}$ & $77.893379^{\circ}$ \\
\hline
\end{tabular}

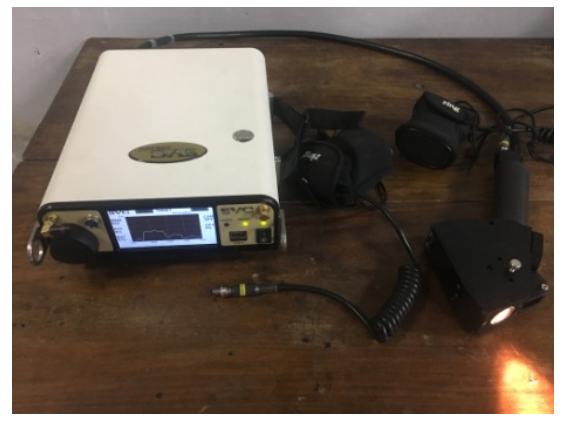

Figure 2.Sepctro-radiometer instrument set up

\begin{tabular}{|c|c|}
\hline Spectral Range & $350-2500 \mathrm{~nm}$ \\
\hline Channels & $1024,2000+$ resampled \\
\hline $\begin{array}{c}\text { Spectral Resolution } \\
\text { (FWHM) }\end{array}$ & $\leq 2.8 \mathrm{~nm}, 700 \mathrm{~nm}$ \\
\hline Minimum Integration & 1 millisecond \\
\hline Battery Type & $7.4 \mathrm{~V}$ lithium ion \\
\hline Digitization & $16 \mathrm{bit}$ \\
\hline Wavelength Repeatability & $0.1 \mathrm{~nm}$ \\
\hline $\begin{array}{c}\text { Noise Equivalent } \\
\text { Radiance }\end{array}$ & $\leq 0.8 \times 10^{-9} \mathrm{~W} / \mathrm{cm}^{2} / \mathrm{nm} / \mathrm{sr} @ 700$ \\
$\mathrm{~nm}$
\end{tabular}

Table 6.Specifications of SVC XHR-1024 spectro-radiometer

SVC XHR-1024 is supported with easy to install and a user friendly application for downloading spectral dataset from spectro-radiometer, store data in different file format, visualizing it in graphical format and performing basic processing. Figure 3(b) shows the spectral-response visualization over SVC PC Data Acquisition software for MT-4 mango tree. 


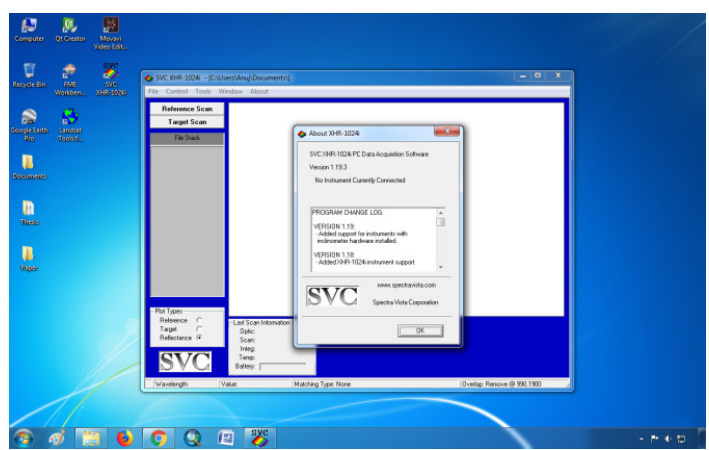

Figure 3. (a)Specifications of SVC PC Data Acquisition Software

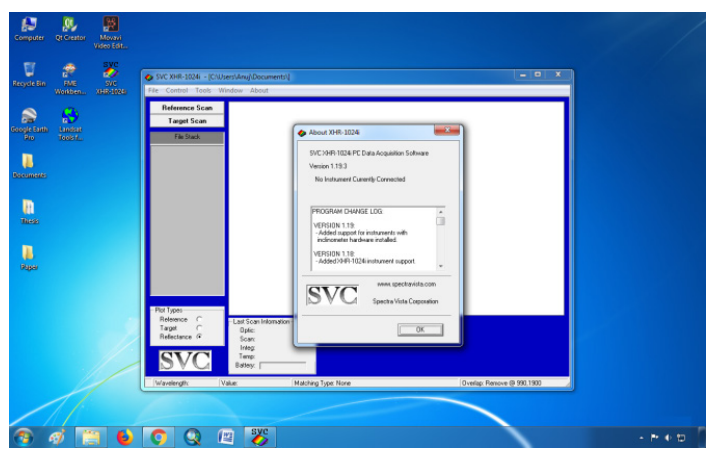

Figure 3. (b) Spectral-response visualization over SVC PC Data Acquisition software for MT-4 mango tree

\section{METHODOLOGY}

The methodology adopted for the assessment of different health parameter in Mango tree is presented in the figure 4. This methodology uses different remote sensing indices to measure the four different pigments in order to describe the health of leaf of Mango tree. Chlorophyll is the primary pigment which governs the Photosynthesis process is measured using four different remote sensing indices. Carotenoid is the secondary pigment present in the leaves to control the over temperature is assessed with five different remote sensing indices. Anthocyanin, secondary pigment present in the leaves, provides ant oxidative and antimicrobial properties is evaluated with three remote sensing indices. Water content which is a vital life element is measured with five different remote sensing indices. Four different mango trees are chosen inside the corridor of IIT Roorkee campus and four mango trees are selected around NH58. In order to compute the impact of pollution on Mango trees, the sample leaves are collected and their spectral responses are evaluated with SVC XHR-1024 and discussed with remote sensing indices. Figure 6 presents mango tree id their pictorial view and collected sample.

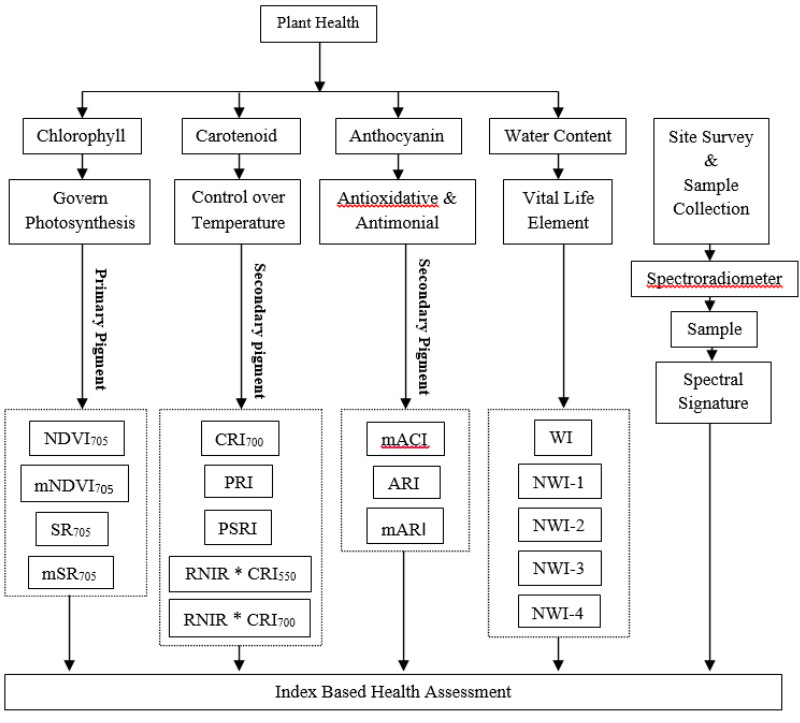

Figure 4.Methodology adopted for tree health assessment

As shown in the figure 2, laser gun is directed towards mango leaves in different envelop and spectral response is visualized over LCD display of control panel. The data are stored for future reference once they satisfy the stability. SVC PC Data Acquisition software is used for the visualization and processing of the resulted spectral responses. Now sequentially each selected sample spectral indices method is implemented and results are computed.

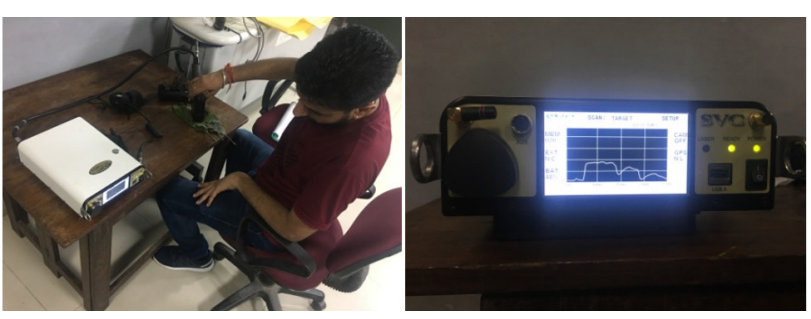

Figure 5.Laser guided spectral reflectance measurement for mango leaves and recorded spectral signature over LCD display 


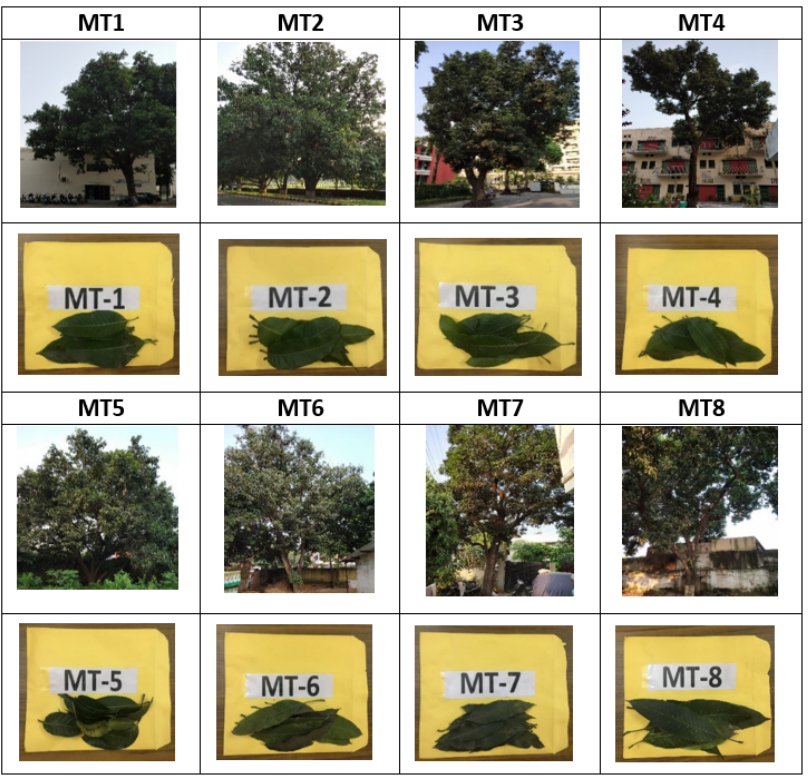

Figure 6.Mango Tree and corresponding leaves samples inside and outside IIT Roorkee campus

\section{RESULTS AND DISCUSSION}

Spectral response curves of the mango tree present inside the campus are shown in the figure 7 likewise, response curves of mango trees present outside the campus are shown in the Figure 8. Results obtained for different tree health parameters are summarized in figure 9, 10,11and 12. Figure 9 depicts the chlorophyll variation in mango tree leaves inside and outside the campus. It can be seen that tree planted. Figure 10 shows Carotenoid variation in mango tree leaves using different indices. It can be noticed that Carotenoid content is less in mango tree planted across the road. Figure 11 presents anthocyanin variation in selected tree samples. It is noted that similar to other pigments anthocyanin concentration is also less in outer mango tree. Figure 12 shows water content variation in selected samples. Water content variation is similar in inside and outside trees and there is no significant conclusion can be drawn on the basis of current sample size.

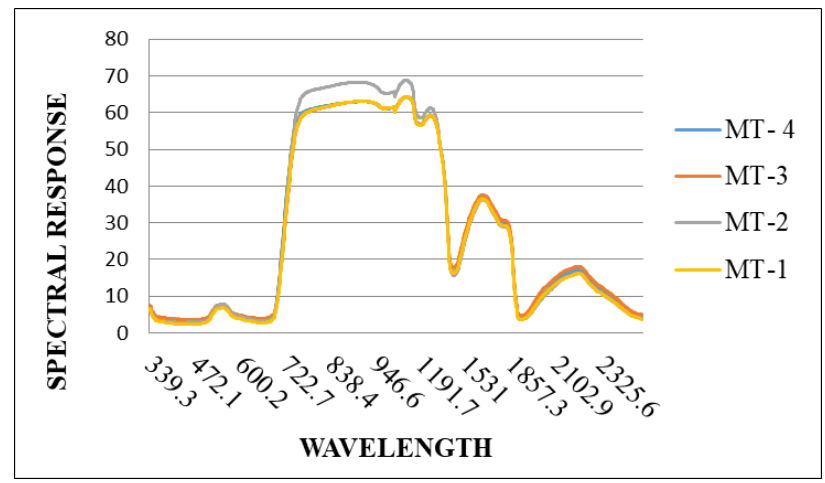

Figure 7.Spectral response curve for four different mango trees inside campus

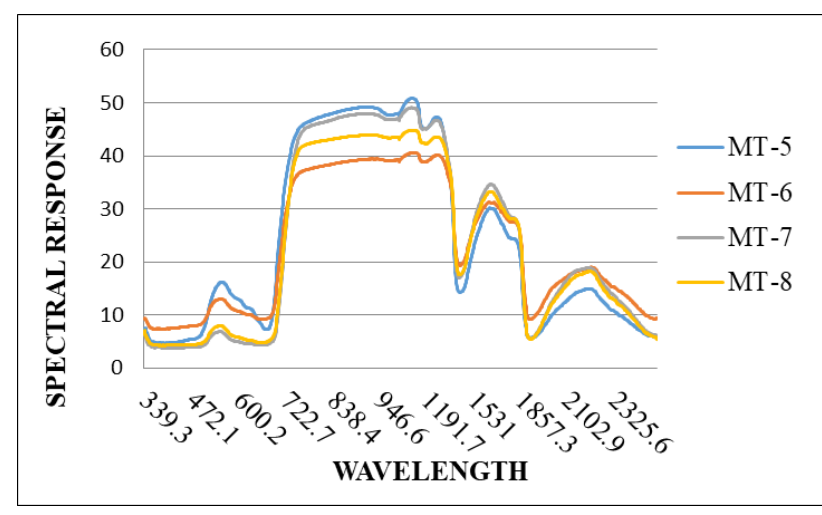

Figure 8.Spectral response curve for four different mango trees outside campus

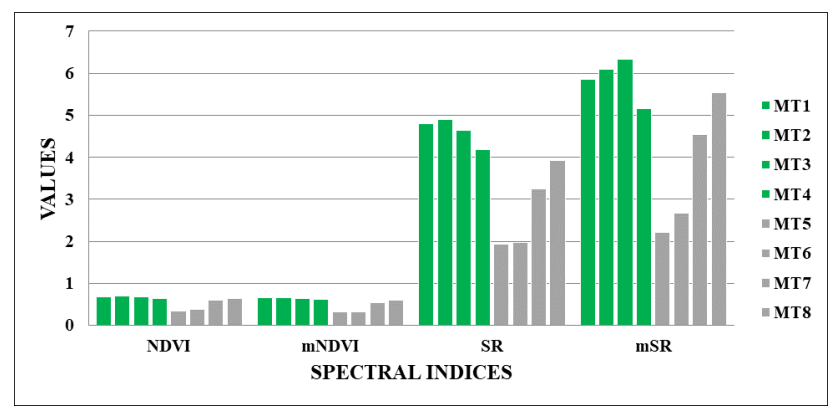

Figure 9.Comparison of different spectral indices for chlorophyll content in selected mango tree dataset

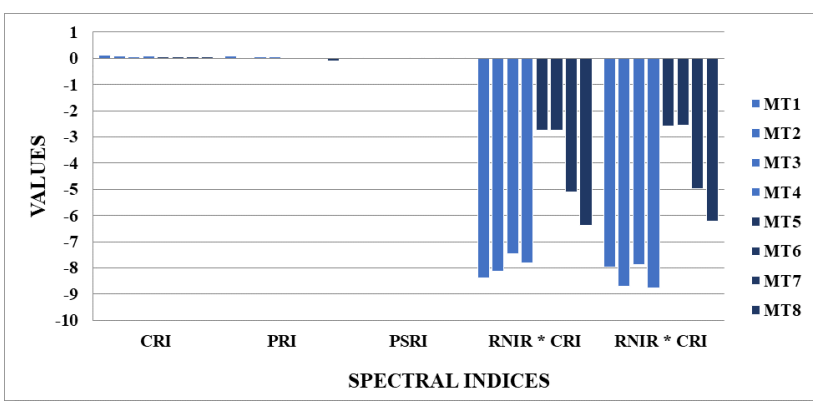

Figure 10.Comparison of different spectral indices for Carotenoid content in selected mango tree dataset

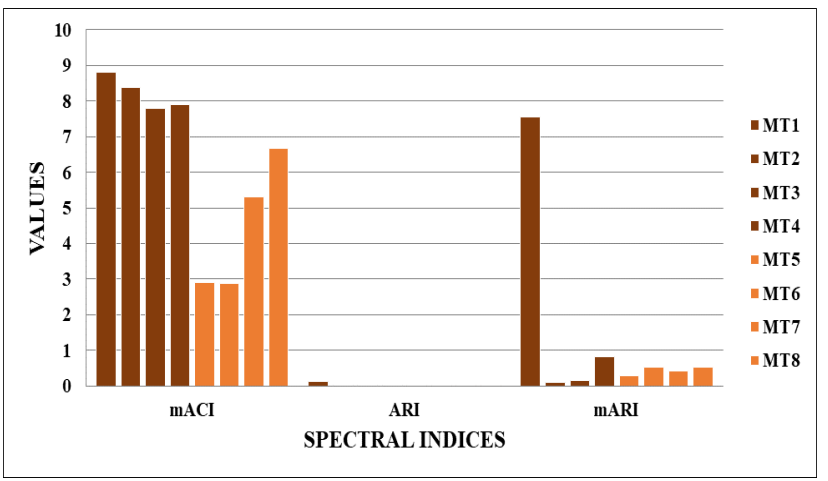

Figure 11.Comparison of different spectral indices for anthocyanin content in selected mango tree dataset 


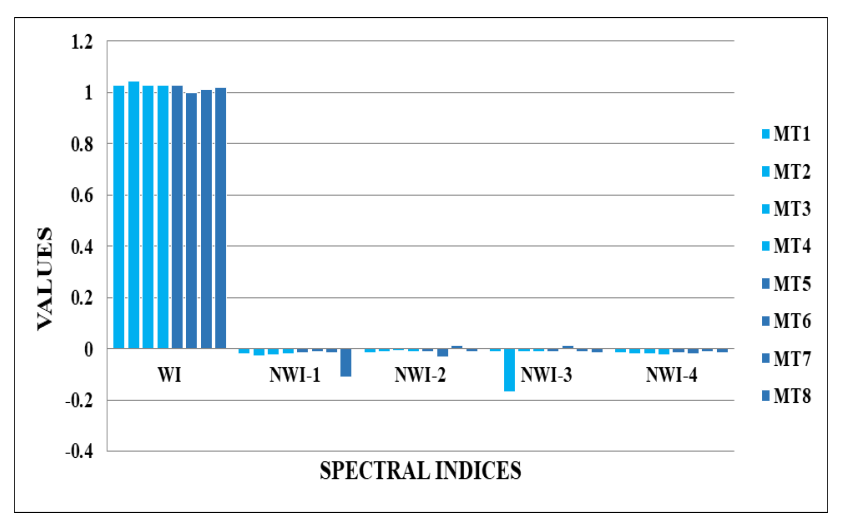

Figure 12.Comparison of different spectral indices for water content in selected mango tree dataset

\section{CONCLUSION}

Current Study is a unique implementation of remote sensing in precision agriculture where implementation of basic remote sensing technique become useful in understanding the influence of deteriorating climate around national highways over the nearby trees.

The study can be further extended to incorporate the impact of pollution on different trees and plants. Under the controlled environment where type and amount of pollution can be measured and their interaction with healthy tree can be quantified is the future scope of research.

\section{ACKNOWLEDGEMENTS (OPTIONAL)}

The authors would like to thank National Land Record Modernization Project-Chhattisgarh Project No. CED- 6097 and Indian Institute of Technology Roorkee for providing funding and facilities for this research.

\section{REFERENCES}

Babar, M. A., Reynolds, M. P., Van Ginkel, M., Klatt, A. R., Raun, W. R., \& Stone, M. L. (2006). Spectral reflectance indices as a potential indirect selection criteria for wheat yield under irrigation. Crop Science, 46(2), pp. 578-588.

Brunekreef, B., \& Holgate, S. T. (2002). Air pollution and health. The lancet, 360(9341), pp. 1233-1242.

Chen, J. C., Yang, C. M., Wu, S. T., Chung, Y. L., Charles, A. L., \& Chen, C. T. (2007). Leaf chlorophyll content and surface spectral reflectance of tree species along a terrain gradient in Taiwan's Kenting National Park. Bot Stud, 48, pp. 71-77.

Ciesla, W. M. (2000). Remote sensing in forest health protection.

Datt, B. (1998). Remote sensing of chlorophyll a, chlorophyll b, chlorophyll $\mathrm{a}+\mathrm{b}$, and total carotenoid content in eucalyptus leaves. Remote Sensing of Environment, 66(2), pp. 111-121.

Dubayah, R.O., Swatantran, A., Huang, W., Duncanson, L., Tang, H.,Johnson, K., Dunne, J.O., Hurtt, G.C., 2017. CMS: LiDAR-derived Biomass, Canopy Height and Cover, Sonoma
County, California, 2013. ORNL DAAC, Oak Ridge, Atzberger, C. (2013). Advances in remote sensing of agriculture: Context description, existing operational monitoring systems and major information needs. Remote Sensing, 5(2), pp. 949-981.

Gitelson, A. A., Chivkunova, O. B., \& Merzlyak, M. N. (2009). Nondestructive estimation of anthocyanins and chlorophylls in anthocyanic leaves. American Journal of Botany, 96(10), pp. 1861-1868.

Jensen, J. R., \& Lulla, K. (1987). Introductory digital image processing: a remote sensing perspective.

Manion, P. D. (1981). Tree disease concepts. Prentice-Hall, Inc...

McLaughlin, S. B., McConathy, R. K., Duvick, D., \& Mann, L. K. (1982). Effects of chronic air pollution stress on photosynthesis, carbon allocation, and growth of white pine trees. Forest Science, 28(1), pp. 60-70.

Mulla, D. J. (2013). Twenty five years of remote sensing in precision agriculture: Key advances and remaining knowledge gaps. Biosystems engineering, 114(4), pp. 358-371.

Nowak, D. J., Crane, D. E., \& Stevens, J. C. (2006). Air pollution removal by urban trees and shrubs in the United States. Urban forestry \& urban greening, 4(3-4), pp. 115-123.

Penuelas, J., Filella, I., Serrano, L., \& Save, R. (1996). Cell wall elasticity and water index (R970 nm/R900 nm) in wheat under different nitrogen availabilities. International Journal of Remote Sensing, 17(2), pp. 373-382.

Peñuelas, J., Pinol, J., Ogaya, R., \& Filella, I. (1997). Estimation of plant water concentration by the reflectance water index WI (R900/R970). International Journal of Remote Sensing, 18(13), pp. 2869-2875.

Pope III, C. A., Burnett, R. T., Thun, M. J., Calle, E. E., Krewski, D., Ito, K., \& Thurston, G. D. (2002). Lung cancer, cardiopulmonary mortality, and long-term exposure to fine particulate air pollution. Jama, 287(9), pp. 1132-1141.

Sampson, P. H., Mohammed, G. H., Noland, T. L., Irving, D., Colombo, S. J., Zarco-Tejada, P. J., ... \& Treitz, P. M. (2000). The bioindicators of forest condition project: a physiological, remote sensing approach. The Forestry Chronicle, 76(6), pp. 941-952.

Schulze, E. D., Lange, O. L., \& Oren, R. (Eds.). (2012). Forest decline and air pollution: a study of spruce (Picea abies) on acid soils (Vol. 77). Springer Science \& Business Media.

Seaton, A., Godden, D., MacNee, W., \& Donaldson, K. (1995). Particulate air pollution and acute health effects. The lancet, 345(8943), pp. 176-178.

Seelan, S. K., Laguette, S., Casady, G. M., \& Seielstad, G. A. (2003). Remote sensing applications for precision agriculture: A learning community approach. Remote Sensing of Environment, 88(1-2), pp. 157-169.

Tiwari, A., Suresh, M., \& Rai, A. K. (2014). Ecological Planning for Sustainable Development with a Green 
Technology: GIS. International Journal of Advanced Research in Computer Engineering \& Technology (IJARCET), 3(3), pp. $2278-1323$.

Wark, K., \& Warner, C. F. (1981). Air pollution: its origin and control.

Xiao, Q., \& McPherson, E. G. (2005). Tree health mapping with multispectral remote sensing data at UC Davis, California. Urban Ecosystems, 8(3-4), pp. 349-361.

Yang, J., McBride, J., Zhou, J., \& Sun, Z. (2005). The urban forest in Beijing and its role in air pollution reduction. Urban forestry \& urban greening, 3(2), pp. 65-78. 